12 Methods for studying information provision, networking and communication in patient support groups

\author{
Cristina Vasilica and Paula Ormandy
}

\title{
12.1 Introduction
}

The chapter provides an overview and critical analysis of the methods used to study information behaviour in the context of online communication. In a healthcare paradigm, traditionally focused on offline communication models such as leaflets or face-to-face information provision, advances in mobile and online technologies provide new communication channels (Atkinson and Castro, 2008). Information seeking behaviour, new models of engagement, and communication using social media, are discussed drawing on real-life social experiences of people, managing a long-term condition, and their engagement in an online peer support group. For example, one individual, managing chronic kidney disease, is part of a local online peer support group designed for renal patients: the Greater Manchester Kidney Information Network (GMKIN). Don (a pseudonym) realised after reading online about other people's experiences of managing the disease that 'My journey has not been easy but it has been absolutely a piece of cake compared to what other people gone through and that has made me realise that perhaps my quality of life is better than what I was perceiving it' (Vasilica, 2015b, 202). Throughout the chapter, patient experiences like this highlight the impact real-life patients' stories have on other people's perceived quality of life. In Don's view, and the views of other patients that we followed in a longitudinal study for almost two years, the narratives shared on the network were novel, and informative. They uncovered different coping mechanisms, ways of managing symptoms, and helped patients to live well with the condition.

In reality the engagement of patients remains a challenge, despite the technological developments and excitement associated with such technologies. The chapter examines how engagement with social media is sustained as a result of empowering patients to become co-producers of health information, increasing the novelty of information shared, the sociability and continuous peer support. Indeed, using social media within the technological mix enables researchers or practitioners to involve patients in the co-production and sharing of information that is relevant, timely, understandable and accessible, to satisfy their information needs. Activity theory is used to connect the key concepts explored: information needs; information behaviour and social connections; and the power of social media.

\subsection{Information behaviour}

Evidence suggests that an information need occurs when an individual recognizes an information gap which, in their perception, is essential to accomplish a goal (Case, 2007). People managing a long-term condition use information to achieve goals to foster self-management, promote independence, improve self-esteem and to live a normal life which, coupled with symptom management and aspects of treatment, prevent further complications, improving the chances of survival (Davies, 2010; Ormandy and Hulme, 2013). They engage in the process of finding information at different points of their illness trajectory. Extensive research has been carried out to understand the information behaviour process (Robson and Robinson, 2013); therefore, this section mainly gives an indication of the key theoretical frameworks developed to capture information need, information seeking and information searching. These models act as a basis for other research in the field.

Cole (2011) conceptualizes an information need as a black box underpinned by three categories: (1) information behaviour, (2) context and (3) human condition, the latter seen as a holistic approach to information need. Overall, Cole's theory is presented in the context of information retrieval (Savolainen, 2012), where information behaviour is concerned with information search, information seeking and information use. Wilson, over the years, has introduced a series of frameworks/models, which portray information behaviour as the interplay of theoretical concepts. Information need develops, then the searching process and the contextual factors inhibit or support the seeking process (Wilson, 1999). The models have been expanded to include a list of characteristics within information seeking (Ellis, 1989), and findings drawn from both consumer research and health information management (Wilson, 2007). Ellis (1989) adopted Glaser and Strauss' grounded theory approach to establish the information seeking steps: starting, chaining, browsing, differentiating, monitoring and extracting. Kuhlthau's information search process (ISP) adds a new dimension, focusing on the interrelationships between cognitive (thoughts), affective (feelings) and physical factors (brainstorming, browsing) that occur at each stage of the search process (Kuhlthau, 2004). 
Whilst Ellis (1989) and Kuhlthau (1993) are focused primarily on the information seeking process, Dervin's sense-making is concerned with what users 'really think, feel, want and dream', outlining how individuals make sense of the information received (Dervin, 1992, 39).

Researchers have attempted to develop health-specific information seeking models either focused on patients or practitioners. Gorman (1995) sought to clarify the information seeking to inform patient care of clinicians in primary care and explored the concepts of unrecognized need, recognized need, pursued and satisfaction of information need. Other researchers expanded on Gorman's concepts and revealed that patients have recognized, unrecognized and deferred needs (Ormandy, 2008; Alzougool, Chang and Gray, 2008).

In the renal field, Ormandy (2008) developed an information need study building on the work of theorists such as Wilson (1981), Dervin (1992) and Case (2007). The study identified that for patients, such as Don, the main priorities were related to information about illness self-management, complications, and physical symptoms. In Ormandy's research, the information concerned with how the illness impacts on daily activities, the treatment available and coping with life was considered by patients as less important than psychological concerns and coping strategies, which activated other information needs. The findings resonate within research on patient need (Rutten et al., 2005; Astin et al. 2008; Franssen et al., 2009; Van Weert et al., 2013; McNair, 2013).

The growth of digital technology is believed to change the information seeking patterns of users (Xie, 2007). Wilson (2004) suggested that users are adopting simple search strategies and that systems must be designed to reduce the complexity of the topic searched or provide an interactive search process for complex requirements. Patients find it easier to access health information via the internet, and similarly information providers found the internet a useful way of distributing information in different ways. More recently, the rise of social media has created digital tools that enable patients to share and rate their experiences of health care, and actively access information (Rozenblum and Bates, 2013). Whilst patients demonstrate increased trust in the accuracy of medical institutions and information from health professionals (McMullan, 2006), online technologies have become a popular resource to access health information (Beaudoin and Hong, 2011; Song and Chang, 2012). Approximately $80 \%$ of internet users are seeking information online (Gruzd, Staves and Wilk, 2012). Patients search the web for information related to nutrition or diet, medication side effects, symptoms, alternative treatment options, and second opinions. Social media, networks such as Facebook and Twitter, are beneficial in reaching a wider patient population, from different ethnic backgrounds, to provide education, enable social engagement and change behaviour (Shaw and Johnson, 2011).

\subsection{The powerful future - Social connectivity and information provision}

Mark Zuckerberg, founder of Facebook, indicated that his original idea for creating social media was based on the ambition to achieve social change and a connected world: 'I'd love to improve people's lives, especially socially... Making the world more open is not an overnight thing. It's a 10-15 year thing' (Zuckerberg, n.d.). Don, reinforced the significance of social connectivity for patients; 'I think I just needed that reassurance that I wasn't alone, I drew an awful lot from that' (Vasilica, 2015a).

The entire internet started as a bulletin board system, which enabled users to share information (Kaplan and Haenlein, 2010). Then the original idea of user generated content (UGC) began with Wikipedia, but key to its expansion was the 'like' button introduced by Facebook in 2008. Over the years the use of social technologies has expanded, from just information exchange to developing friendship, connections, social movements and social support: a movement to harness collective intelligence (O'Reilly and Battelle, 2009). Although, most organizations are yet to use social media at full capacity.

The term Web 2.0 was first introduced in 2004 to set the boundaries of a new technology, which encompassed platforms continuously updated by users; creating combinations (or mashups) from one or multiple sources, then adding their own knowledge and perspective, generating a network effect (O'Reilly, 2005). UGC was the general term coined in 2005 to describe the various forms of digital content created by Web 2.0 users (Kaplan and Haenlein, 2010). Social media technology blurs the boundaries between reception and production of information (Betsch et al., 2012) and UGC relates closely to the concept of 'word of mouth', but in an electronic context (Smith et al., 2012). UGC takes 
a variety of forms including tweets (Twitter) status updates (Facebook), videos (Youtube, Vimeo), limited time availability information (Snapchat), and blogging. It fulfils three basic requirements; it must be publicly available to a group of people, the content must be innovative and not copied directly from a different source and, it must be created separately from professional routines.

The body of social media research emerged from various research studies on friendship (Boyd, 2004; Boyd, 2006; Joinson, 2008; Boyd and Ellison, 2007), social capital (Ellison, Steinfield and Lampe., 2006; Ellison, Steinfield and Lampe, 2011), information and emotional support (Eysenbach et al., 2004; Buchanan and Coulson, 2007; Coulson, Buchanan and Aubeeluck, 2007; Malik and Coulson, 2010), and impact on quality of life and health (Roblin, 2011; Chan and Dicianno, 2011; Merolli, Gray and Martin-Sanchez, 2013; Merolli et al., 2015).

The rise of social media has resulted in many patients no longer relying on information just being given; they like to be part of the information production process by offering solutions to problems, comments and sharing their experiences (Adams, 2011; Hardiker and Grant, 2011; Lober and Flowers, 2011). This does not come as a surprise as health professionals' time to respond to patients' queries during a typical interaction is limited (Haase and Loiselle, 2012). Meeting the information needs of different patients is a challenge for modern healthcare (Ormandy, 2008; Schinkel, Schouten and van Weert, 2013).

Social media researchers have observed very different levels of engagement with the media. Groups commonly contrasted are the active or 'posters' and passive or 'lurkers'. Their motivations for engagement are very different (Preece, Nonnecke and Andrews; Rau, Gao and Ding, 2008; Petrovčič and Petrič, 2014). Posters are the members who actively contribute UGC (Schlosser, 2005). They expect reciprocity, alongside gaining enjoyment in helping others and new knowledge which motivate them to post. The user generated information process is influenced by the enthusiasm of moderators, who offer enjoyable experiences (Lai and Chen, 2014), intimate relationships (Rau, Gao and Ding, 2008) and social capital (Zhao, Ha and Widdows, 2015). Lurkers are defined as passive members who do not post or post fewer messages and learn by observing (Gray, 2004; Petrovčič and Petrič, 2014). Their main reasons for lurking are associated with characteristics of: no immediate need; the need to know the group better before posting; the belief that they are helpful by not posting; not knowing how to use the software; disliking the group dynamics; and believing that the community was not meeting their needs (Preece, Nonnecke and Andrews, 2004). Moreover, lurkers may refrain from posting because of having contradictory views, being afraid of being criticized or judged by other members of the community (Guan, 2006). In health online communities, lurkers may form over $45 \%$ of the users (Nonnecke and Preece, 2000). Interestingly, lurkers refrain from posting or commenting but with time, some might become active users because of reading the content, and becoming familiar with community norms and values (Schneider, von Krogh and Jäger, 2013).

A more complex classification of levels of engagement is given in the Social Technographics Ladder (Bernoff and Li, 2010 where the ladder represents the hierarchical order of user participation within social media. The most active individuals are creators, followed by critics, collectors, joiners, spectators and inactive. Participants can satisfy one or more roles on the ladder (Bernoff and Li, 2010).

Brodie et al. (2011), however, brand online communities' user engagement as sub-processes which take different forms: sharing, co-developing, learning, socialising, and advocating. Sharing is a behavioural and cognitive engagement sub-process, where users actively generate (co-create) information from personal knowledge and experience, along with learning and acquiring new knowledge from the information. Co-developing is associated with engagement to assist in the development of new products, services, brands or brand meanings. Users are socialising because of the benefits of two-direction interaction, in which they develop attitudes, social norms and common purpose, and advocate and recommend the community to others (Brodie et al., 2011).

Schneider, von Krogh and Jäger (2013) identified the role of expert members, who contribute to the welfare of the community, actively engage and need new information, to discover new ideas, but who are not necessarily actively seeking new knowledge. Evidence denotes that the information spread online, for example patients' personal blogs, forums, wikis, enables patients to prepare for or decide on treatment, manage symptoms and adverse effects, reduceing uncertainty and fulfiling information need (Bender et al., 2013; Schneider, von Krogh and Jäger , 2013; Vennik et al., 2014). 


\subsection{Design of the GKMIN site}

The Greater Manchester Kidney Information Network (GMKIN) (gmkin.org.uk) is an innovative joint venture between a local Kidney Patient Association (KPA) and academia, in response to patient demand to develop a mechanism to connect patients. Research suggested that patient information needs with respect to the reality of managing kidney disease in everyday life were not being met, and talking with peers would be beneficial (Ormandy, 2008). With that in mind, innovative ways to enable patients to access information from the experienced kidney patient community were sought. The collaborative project, originated in August 2012, was informed and shaped by meetings with patients and local practitioners.

Drawing on evidence from information need, social media and engagement behaviour theorists it was evident that social media could be used to enable kidney patients to support each other, and to develop a deeper understanding as to how patients used the different features and evidence of preferred levels of engagement. From the outset, the impact of social media on information provision for patients was examined, and their self-efficacy (extent of their belief in their ability to complete tasks) and engagement were evaluated. Interest focused on the dynamics of social media interactions, how community moderators worked, how patients' roles evolved and the effects of health practitioner involvement.

The evidence provided in this section comes from the longitudinal study of patients with a chronic kidney disease who had access to GKMIN. The network, set up in 2013, was a user-centered design (UCD), eliciting informal feedback on reference and prototype versions of the network (Norman, 1998). From the inception stage, the network and the platform were developed using theory and experience of similar research projects involving social media. The Information Search Process (Kuhlthau, 2004) influenced the design, assuming that users would follow a similar search process online, primarily when they received contradictory information and required support (Warner and Procaccino, 2004). The system was designed to support patients in managing complexity (Wilson, 2004), by signposting to information and offering peer-to-peer support. The informational components addressed the needs identified by Ormandy and Hulme (2013).

The engagement of users was essential and the idea of engagement was viewed as a positive experience 'characterized by attributes of challenge, positive effect, insurability, aesthetic and sensory appeal, attention, feedback, variety/novelty, interactivity and perceived control' (O'Brien and Toms, 2008: 949). Furthermore, to build a sustainable community, the principles of social capital were applied (Putnam, 2000; Szreter and Woolcock, 2004), recognizing that ties amongst members stimulate the process of posting (Law and Chang, 2012). GMKIN developed into a social and informational intervention using the following social media tools:

- GMKIN Platform - bespoke online system developed to enable patients to access information and/or register anonymously to post blogs and comments or use the forum to ask/respond to specific questions. Clinicians joined the network submitting blogs and useful information such as diet information, reporting developments at the local hospital, and communicating research opportunities.

- GMKIN on Facebook - patient-to-patient closed social networking group. The group was initially open to recruit local patients, then closed to protect the confidentially of the information shared.

- GMKINet - Twitter account to: engage in conversations on health matters including chronic kidney disease (CKD), share and build a follower base to increase patient involvement, greater access to patient opinion, and raise GMKIN profile.

Chris (pseudonym) a patient involved in GMKIN describes the interoperability of the three different media: 'It's almost like, if you imagine a university campus, Twitter is like the notice board and then Facebook is the student union and then the website is like the resource library. So it kind of depends on what you are looking for' (Vasilica, 2015b: 236).

Crucial to the project was the development of a sustainable community of patients, who share a positive and respectful relationship amongst themselves. The existing research on social capital exposed that bonding, bridging and linking contribute significantly to online relationships, although not explicitly in reference to the behaviours of community moderators (Kobayashi, 2010). Indeed, there 
were very few examples on how to achieve the bonding, bridging and linking in practice. Particularly how community moderators could manage user comments to build positive relationships, avoid unacceptable language/behaviours and stimulate user-generated content. One of the questions underpinning the project was how to create sustainable patient engagement strategies using social media and social capital constructs.

One of the authors (Cristina Vasilica) adopted the community moderator role, drawing on her expertise of managing online communities. An engagement strategy was developed, influenced by community of practice concepts (CoP) which suggest that collective learning occurs in social settings (Lave and Wenger, 1991) and bonding social capital (Putnam, 2000). It primarily focused on observing users, to learn their needs and preferences, adopting a friendly approach, listening to the voice of the community, stimulating leaders and providing content that stimulated their engagement. Welcoming messages were posted to get to know new members, asking them to introduce themselves and promoting GMKIN functionalities, which influenced other members of the group to join and greet new members. Fundamental to the role, was developing meaningful relationships among users through light discussions, sociability and supporting prospective leaders. A classic example of a light discussion involved a simple garden photo, posted by the community moderator during a period of silence, which reverberated with the community members in an unexpected way:

'...when you post pictures of your home town and your tomatoes ... and I think the more you know people the more you are interested in what they say and it's... if you start to know someone it's more interesting to know what they are saying than it is if they are just a complete stranger' (Chris) (Vasilica, 2015b, 146)

'And your flowers [picture of garden], I mean it is part of it you don't have to be thinking of dread and doom serious as it is I mean I say thank God I am not on dialysis' (Jon) (Vasilica, 2015b, 146)

'I’ll apply for a job in your garden...(laughs)' (Mark) (Vasilica, 2015b, 146)

Supporting prospective leaders played an important part in achieving a community that was sustainable beyond the initial period of research. The patient leaders (in the apprenticeship role), who joined the community as newcomers (initially engaged in peripheral participation) gained experience and learnt from the moderator practice and continuous discussions contributing to the growth, establishment and now sustainability of GMKIN.

\subsection{Levels of engagement}

Research (Section 12.3) has categorized the various levels of engagement in creating and distributing content. The evidence observed within GMKIN indicated that patients engaged on different levels: the highest level contribution (influencer), mid-level contribution (conversationalist) and low level (browser) (Vasilica, 2015b). These levels were not a segmentation of a particular group; often those in higher groups shared all three levels (Table 12.1). Despite benefiting from the information shared on GMKIN, a passive role was preferred when patients lacked sufficient experience of the illness and had primarily joined to gain new knowledge. Patients sharing the browser role demonstrated an increased confidence and self-efficacy similar to the influencer and conversationalist, which supports the suggestion that social interaction is linked to behaviour change.

Table 12.1 - Levels of engagement

\begin{tabular}{|c|c|c|}
\hline Influencer & Conversationalist & Browser \\
\hline $\begin{array}{l}\text { The role involved more } \\
\text { responsibility than just } \\
\text { advocacy. In particular, the } \\
\text { influencer created, shared } \\
\text { information whilst focusing on } \\
\text { advocacy and whishing the } \\
\text { community to work for the other } \\
\text { patients involved in the } \\
\text { community. }\end{array}$ & $\begin{array}{l}\text { The role was significant in } \\
\text { influencing members' } \\
\text { engagement by providing } \\
\text { feedback and keeping the } \\
\text { conversations flowing }\end{array}$ & $\begin{array}{l}\text { The browsing mode was a } \\
\text { predominant role, associated } \\
\text { with reading and collecting } \\
\text { information. }\end{array}$ \\
\hline
\end{tabular}


Although the focus of GMKIN was on peer-to-peer support, efforts were made to involve practitioners, who initially expressed concerns that the information provided may be misunderstood by patients. Some viewed their code of practice as an impediment to sharing information or connecting with patients on Facebook, primarily a personal and friendship platform. Patients when asked did not want practitioners as friends on GMKIN or expect then to offer medical advice, more an overseeing role providing reassurance that information shared by other patients was accurate.

'More direction than actual medical advice, because I feel if I wanted medical advice I will rather wait for my appointment' (Donna) (Vasilica, 2015b,184)

'It is up to them if they want to respond or if they just want to sit back like I do and just take on what is going on rather than answering too many questions' (Lucy) (Vasilica, 2015a)

Those practitioners who joined contributed to information provision and observed the discussions. Indeed, patient opinion suggested that the presence of health professionals within the community does not stifle patient-to-patient discussion but provides a level of reassurance and credibility on the network.

'There is someone there who understands the technicality of it much more comfortable, I'll much more express an opinion that was wrong and have someone there with authority behind them to actually correct me rather than engage in argument with someone you know who did not have that authority behind them so I do really do welcome the influx of medical profession into it' (Don) (Vasilica, 2015b, 184)

Social Media is often overlooked for its potential to provide peer-to-peer support and positive health outcome, although GMKIN reinforces confidence in using such media. Health professionals require training to understand social media and Facebook privacy settings, as well as the ability to create groups with whom specific information can be shared. More importantly, clinicians need to treat social media platforms as a mechanism to connect and communicate with patients and not be intimidated by these 'friendship' venues. Adoption of social media should be treated as an intervention, in which all offline rules (privacy, confidentiality) are maintained.

Engagement with social media does not just happen, but is articulated and influenced by those who manage the community, as well as the users themselves. For a community to work and be sustainable it requires all three levels of engagement: producing information highly regarded by patients and influential of positive change in the local community. The results of the study revealed that the majority of patients involved in the research increased their self-efficacy, their knowledge to better self-manage their condition and confidence to seek future employment (Vasilica, 2015b).

\section{6 Social media 'connectivism' through activity theory}

Activity theory originated from the Russian school of thought pioneered by Vygotsky, Leont'ev, and Rubinshtein (Leont'ev 1977, 1978) later continued by a Scandinavian researcher (Engestrom, 1999). Activity theory is a collective activity with norms and rules shared by the community members (community), in which subjects undertake activities motivated by a need (object) and influenced by tools, which enable them to achieve their goals (outcomes). The activity is influenced by the context (a closed group or team or the society) in which it takes place and the influencing mechanisms (norms and the division of labour). The theory acknowledges that the outcome-bounded activity progresses as the knowledge and understanding develops within the mind of the subject involved in the process (Bedny and Karwowski, 2004).

The theory has been applied in various domains, psychology, education, online learning, human computer interaction, system development, information science, digital library development, information retrieval, information seeking behaviour (see Wilson's 2006 work which provides detailed account of the application of activity theory). Other prolific authors have explored the theory in different contexts (Bødker, 1989; Kuutti, 1991; Hjørland, 1997, 2000, 2004; Kaptelinin and Nardi, 2007). 
In the process of information provision and support, people must undertake different activities to transform their goals into desired outcomes. Activity theory appears to provide a conceptual framework to map the journey of social media users from seeking information to health outcomes (Figure 12.1).

Figure 12.1 - Social Media GMKIN CKD application of activity theory (adapted from Engeström, 1987, 78)

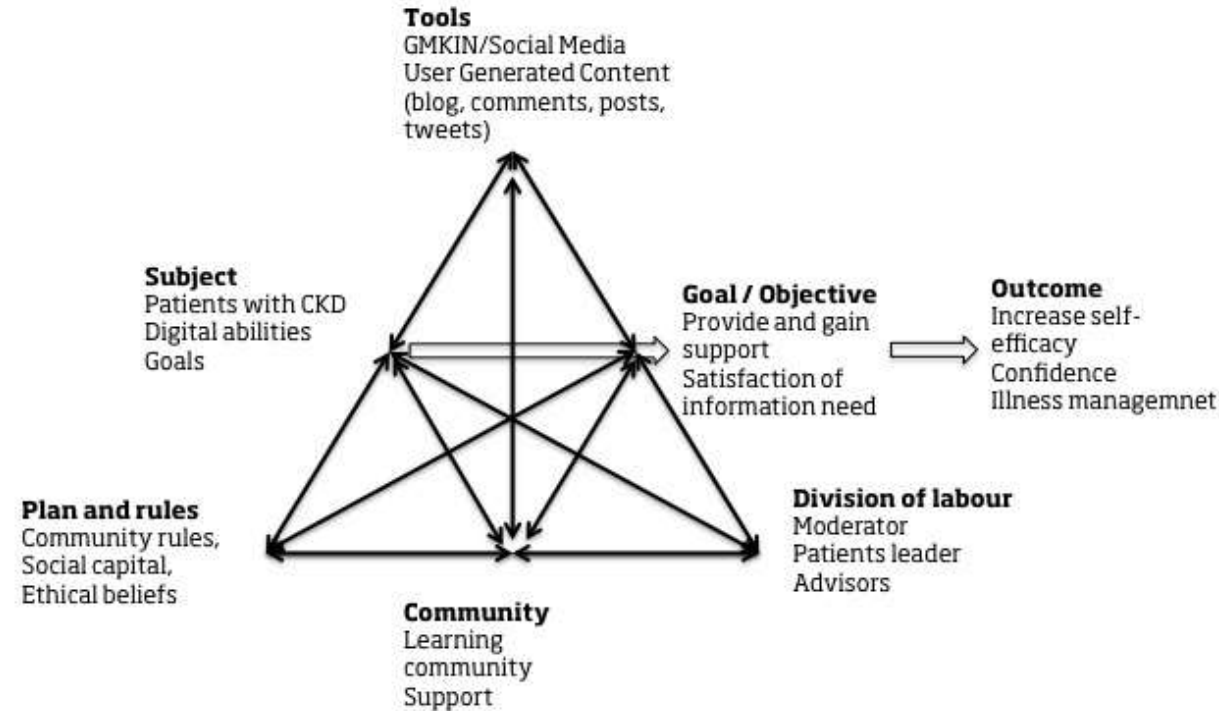

It was envisaged that by setting up the tools to enable patients to talk to one another and provide health information it would satisfy their information need and increase self-efficacy. Amongst the tools, the online community set up on Facebook, the GMKIN platform and Twitter enabled patients to access support and share information in the form of blogs, comments and tweets. The information generated within GMKIN moved beyond patient stories to include biomedical information, and presented new medical advances. Patients identified that information was the main contributor to remaining engaged, confirming studies that indicated that social media should help elicit patient generated content (Merolli, Gray and Martin-Sanchez, 2013; Applebaum, Lawson and von Scheven, 2013). Kidney patients joined the online groups for information (Buchanan and Coulson, 2007; Mo and Coulson, 2010;

Welbourne, Blanchard and Wadsworth, 2013)Welbourne et al., 2013). Sharing information can generate problems, with information reliability often a cause for concern within social media communities (Hughes et al., 2008; Adams, 2010 Fernandez-Luque, Karlsen and Melton, 2012; Moorhead et al., 2013). This problem may be alleviated if healthcare practitioners join the network, and can reassure patients. However, ethical issues associated with practitioners' codes of practice remain one of the most significant challenges faced during the development and running of GMKIN.

The rules of the community are associated with different levels of use and the division of labour. For example, the community manager's role was to influence the development of relationships amongst members through implementing social capital concepts (Putnam, 1995; Putnam, 2000; Woolcock, 2001; Szreter and Woolcock, 2004), enabling members to gradually become acquainted with the community norms and regulations: 
know the difference between $H D$ and $P D, I$ do now but even before dialysis that was it I did not realise that was different forms of dialysis and this is something I picked up' (Jon) (Vasilica, 2015b, 173) 'You reminded me so many times it will develop it will happen, we find a subject that people are interested in classic example is the photograph of your garden and the conversations we had coming out of that nothing at all to do with CKD' (Don) (Vasilica, 2015b, 146).

Community is an important pillar of social media. Indeed having an information system without a community is representative of a ghost town. Today, 'connectivism' suggests that knowledge is directly linked to a network and the minds of connected people (Siemens, 2005). Information and social support contribute to sustained engagement, which then triggers learning and knowledge. Similar with CoP principles, the domain of learning and increase in knowledge is distributed over a period of time (Wenger, McDermott and Snyder, 2002). Members (at all levels of engagement, especially, conversationalist and influencing) initially join the community as newcomers and through engaging in the process of generating information make the community work (Lave and Wenger, 1991). Patients at different stages of chronic kidney disease with varied digital skills, joined the network having a goal in mind, the majority expressing their readiness to offer something to others in a similar situation.

'The biggest goal is to show another person that it is possible... that even if you are suffering from this illness you can still get out there and still do things' (Vicky,) (Vasilica, 2015b:142)

'If I write a blog and it helps one person it is worth it' (Jannie) (Vasilica, 2015b:142)

Patients' goals are known to influence engagement (O'Brien and Toms, 2008; Hollebeek, 2011). At the initial point of engagement, the user has a specific or experiential goal in mind, triggered by motivations and interest, and is attracted by the aesthetic appeal or novelty of the system (O'Brien and Toms, 2008).

\subsection{Conclusion}

This chapter highlighted how emerging technologies could be used to engage patients in online interventions, which in turn triggers positive social and health outcomes.

For this to happen the community moderators (influencers) have to take an active role in stimulating conversations, developing meaningful relationships and understanding the community needs. The presence of health practitioners increases the level of reassurance and credibility on the network.

By connecting with online communities, patients access informational support, which satisfies their information need (Vasilica, 2015b). Potentially, social learning via social media would further encourage patients to engage with their condition, improve self-management and in some cases, set them on a path to becoming patient leaders. Connectivism is crucial in alleviating loneliness and enabling patients to find an important lifeline and non-judgemental company. As a result, patients increase confidence with their own competence in dealing with their condition.

\section{Reference}

Adams, S. A. (2011) Sourcing the Crowd for Health Services Improvement: the reflexive patient and "share-your-experience" websites, Social Science \& Medicine, 72 (7), 1069-1076. doi:10.1016/j.socscimed.2011.02.001

Adams, S. (2010). Revisiting the Online Health Information Reliability Debate in the Wake of "Web 2.0": An Inter-disciplinary Literature and Website Review. International Journal of Medical Informatics, 79(6): 391-400. 
Alzougool, B., Chang, S. and Gray, K. (2015) A New Scale to Measure the State of an Informal Carer's Information Needs: development and validation, Journal of Consumer Health on the Internet, 19 (3-4), 200-218. doi:10.1080/15398285.2015.1089396

Applebaum, M. A., Lawson, E. F. and von Scheven, E. (2013) Perception of Transition Readiness and Preferences for Use of Technology in Transition Programs: teens' ideas for the future, International Journal of Adolescent Medicine and Health, 25 (2), . doi:10.1515/ijamh-2013-0019

Astin, F., Closs, S. J., McLenachan, J., Hunter, S. and Priestley, C. (2008) The Information Needs of Patients Treated with Primary Angioplasty for Heart Attack: an exploratory study, Patient Education and Counseling, 73 (2), 325-332. doi:10.1016/j.pec.2008.06.013

Atkinson, R. D. and Castro, D. (2008) Digital Quality of Life: understanding the personal and social benefits of the information technology revolution, SSRN Electronic Journal, doi: $10.2139 /$ ssrn. 1278185

Beaudoin, C. E. and Hong, T. (2011) Health Information Seeking, Diet and Physical Activity: an empirical assessment by medium and critical demographics, International Journal of Medical Informatics, 80 (8), 586-595. doi:10.1016/j.ijmedinf.2011.04.003

Bedny, G. Z. and Karwowski, W. (2004) Activity Theory as a Basis for the Study of Work, Ergonomics, 47 (2), 134-153. doi:10.1080/00140130310001617921

Bender, J. L., Katz, J., Ferris, L. E. and Jadad, A. R. (2013) What is the Role of Online Support from the Perspective of Facilitators of Face-to-Face Support Groups? A Multi-Method Study of the Use of Breast Cancer Online Communities, Patient Education and Counseling, 93 (3), 472-479. doi:10.1016/j.pec.2013.07.009

Bernoff, J. and Li, C. (2010) Harnessing the Power of the Oh-So-Social Web, IEEE Engineering Management Review, 38 (3), 8-15. doi:10.1109/emr.2010.5559138

Betsch, C., Brewer, N. T., Brocard, P., Davies, P., Gaissmaier, W., Haase, N., Leask, J.; Renkewitz, F.; Renner, B.; Reyna, V.F.; Rossmann, C.; Sachse, K.; Schachinger, A.; Siegrist, M.; Stryk, M. (2012) Opportunities and Challenges of Web 2.0 for Vaccination Decisions, Vaccine, 30 (25), 3727-3733. doi:10.1016/j.vaccine.2012.02.025

Bodker, S. (1989) A Human Activity Approach to User Interfaces, Human-Computer Interaction, 4 (3), 171-195. doi:10.1207/s15327051hci0403_1

Boyd, D. (2004) Friendster and Publicly Articulated Social Networks. Proceedings of the Conference on Human Factors and Computing Systems - CHI2004. Vienna, Austria, ACM Press: 1279-1282.

Boyd, D. (2006) Friends, Friendsters, and Top 8: writing community into being on social network sites, First Monday, 11 (12). doi:10.5210/fm.v11i12.1418

Boyd, D. M. and Ellison, N. B. (2007) Social Network Sites: definition, history, and scholarship, Journal of Computer-Mediated Communication, 13 (1), 210-230. doi:10.1111/j.1083-6101.2007.00393.x

Brodie, R. J., Hollebeek, L. D., Juric, B. and Ilic, A. (2011) Customer Engagement: conceptual domain, fundamental propositions, and implications for research, Journal of Service Research, 14 (3), 252 271. doi:10.1177/1094670511411703

Buchanan, H. and Coulson, N. S. (2007) Accessing Dental Anxiety Online Support Groups: an exploratory qualitative study of motives and experiences, Patient Education and Counseling, 66 (3), 263-269. doi:10.1016/j.pec.2006.12.011

Case, D. O. (2007) Looking for Information: a survey of research on information seeking, needs, and behavior. Elsevier/Academic Press. 
Chan, W. M. and Dicianno, B. E. (2011) Virtual Socialization in Adults with Spina Bifida, $P M \& R, 3$ (3), 219-225. doi:10.1016/j.pmrj.2010.12.002

Cole, C. (2011) A Theory of Information Need for Information Retrieval that Connects Information to Knowledge, Journal of the American Society for Information Science and Technology, 62 (7), 1216-1231. doi:10.1002/asi.21541

Coulson, N. S., Buchanan, H. and Aubeeluck, A. (2007) Social Support in Cyberspace: a content analysis of communication within a Huntington's disease online support group, Patient Education and Counseling, 68 (2), 173-178. doi:10.1016/j.pec.2007.06.002

Davies, N. J. (2010) Improving Self-Management for Patients with Long-Term Conditions, Nursing Standard, 24 (25), 49-56. doi:10.7748/ns2010.02.24.25.49.c7562

Dervin, B. (1992) From the Mind's Eye of the User: the sense-making qualitative and quantitative methodology. In Glazier, J. D. and Powell, R. R. (eds), Qualitative Research in Information Management. Libraries Unlimited (pp. 61-84).

Ellis, D. (1989) A Behavioural Model for Information Retrieval System Design, Journal of Information Science, 15 (4-5), 237-247. doi:10.1177/016555158901500406

Ellison, N. B., Steinfield, C. and C. Lampe (2006) Spatially Bounded Online Social Networks and Social Capital: The Role of Facebook. Proceedings of the 56th Annual Conference of the International Communication Association. Dresden, Germany: sic.

Ellison, N. B., Steinfield, C. and Lampe, C. (2011) Connection Strategies: social capital implications of Facebook-enabled communication practices, New Media \& Society, 13 (6), 873-892. doi:10.1177/1461444810385389

Engeström, Y. (1987). Learning by Expanding: An Activity-theoretical Approach to Developmental Research. Orienta-Konsultit Oy

Engeström, Y. (1999) Learning by Expanding: ten years after (Trans. F. Seeger). http://lchc.ucsd.edu/MCA/Paper/Engestrom/expanding/intro.htm

Eysenbach, G., Powell, J., Englesakis, M., Rizo, C. and Stern, A. (2004) Health Related Virtual Communities and Electronic Support Groups: systematic review of the effects of online peer to peer interactions, BMJ, 328 (7449), 1166-0. doi:10.1136/bmj.328.7449.1166

Fernandez-Luque, L., Karlsen, R. and Melton, G. B. (2012) HealthTrust: a social network approach for retrieving online health videos, Journal of Medical Internet Research, 14 (1), e22. doi:10.2196/jmir.1985

Franssen, S. J., Lagarde, S. M., van Werven, J. R., Smets, E. M. A., Tran, K. T. C., Plukker, J. T. M., van Lanschot, J.J.B. and de Haes, H. C. J. M. (2009) Psychological Factors and Preferences for Communicating Prognosis in Esophageal Cancer Patients, Psycho-Oncology, 18 (11), 1199-1207. doi:10.1002/pon.1485

Gorman, P. N. (1995) Information Needs of Physicians, Journal of the American Society for Information Science, 46 (10), 729-736. doi:10.1002/(sici)1097-4571(199512)46:10<729::aid-asi3>3.0.co;2-2

Gray, B. (2004) Informal Learning in an Online Community of Practice, Journal of Distance Education, 19 (1), 20-35.

Gruzd, A., Staves, K. and Wilk, A. (2012) Connected Scholars: examining the role of social media in research practices of faculty using the UTAUT model, Computers in Human Behavior, 28 (6), 2340-2350. doi:10.1016/j.chb.2012.07.004

Guan, X. (2006) Reasons for the Formation of Cybernetic Lurkers, Journal of Huaihai Institute of Technology, 4, 79-82. 
Haase, K. R. and Loiselle, C. G. (2012) Oncology Team Members' Perceptions of a Virtual Navigation Tool for Cancer Patients, International Journal of Medical Informatics, 81 (6), 395-403. doi:10.1016/j.ijmedinf.2011.11.001

Hardiker, N. R. and Grant, M. J. (2011) Factors that Influence Public Engagement with eHealth: a literature review, International Journal of Medical Informatics, $\mathbf{8 0}$ (1), 1-12. doi:10.1016/j.ijmedinf.2010.10.017

Hjørland, B. (1997) Information Seeking and Subject Representation. an activity-theoretical approach to information science, Greenwood Press.

Hjørland, B. (2000) Information Seeking Behaviour: what should a general theory look like? The New Review of Information Behaviour Research, 1, 19-33.

Hjørland, B. (2004) Arguments for Philosophical Realism in Library and Information Science, Library Trends, 52 (3), 488-506.

Hollebeek, L. D. (2011) Demystifying Customer Brand Engagement: exploring the loyalty nexus, Journal of Marketing Management, 27 (7-8), 785-807. doi:10.1080/0267257x.2010.500132

Joinson, A. N. (2008) Looking at, Looking up or Keeping up with People?: motives and use of Facebook. In Czerwinski, M., Lund, A. and Tan, D. (eds), Proceedings of the Twenty-Sixth Annual SIGCHI Conference on Human Factors in Computing Systems.. Florence, Italy, Association of Computing Machinery: 1027-1036.

Kaplan, A. M. and Haenlein, M. (2010) Users of the World, Unite! The Challenges and Opportunities of Social Media, Business Horizons, 53 (1), 59-68. doi:10.1016/j.bushor.2009.09.003

Kaptelinin, V. and Nardi, B. (2007) Acting with Technology: activity theory and interaction design, First Monday, 12 (4). doi:10.5210/fm.v12i4.1772

Kobayashi, T. (2010) Bridging Social Capital in Online Communities: heterogeneity and social tolerance of online game players in Japan, Human Communication Research, 36 (4), 546-569. doi:10.1111/j.1468-2958.2010.01388.x

Kuhlthau, C. C. (1993) A Principle of Uncertainty for Information Seeking, Journal of Documentation, 49 (4), 339-355. doi:10.1108/eb026918

Kuhlthau, C. (2004) Seeking Meaning: a process approach to library and information services, 2nd edn, Libraries Unlimited.

Kuutti, K. (1991) Activity Theory and its Applications in Information Systems Research and Design. In Nissen, H.K. Klein, and R. Hirschheim (eds), Information Systems Research Arena of the 90s, North-Holland (pp. 529-550).

Lave, J. and Wenger, E. (1991) Legitimate Peripheral Participation in Communities of Practice Situated Learning: legitimate peripheral participation. In Lave, J. and Wenger, E. (eds) Situated Learning: legitimate peripheral participation, Cambridge University Press.

Law, S. P. and Chang, S. P. (2012) Social Capital and Knowledge Sharing in online communities: A Mediation Model. 45th Hawaii International Conference on System Sciences, 3530-3539

Leont'ev, A. (1977) Activity and consciousness. In Philosophy in the USSR: Problems of dialectical materialism 180-202. Moscow: Progress Publishers. Retrieved February 10, 2017, from http://www.marxists.org/archive/leontev/works/1977/leon1977.htm

Leont'ev, A. (1978) Activity, consciousness, and personality (M. J. Hall, Trans.). Englewood Cliffs, NJ: $\begin{array}{lllll}\text { Prentice Hall. } \quad \text { Retrieved } & \text { February } & \text { 2017, }\end{array}$ http://www.marxists.org/archive/leontev/works/1978/index.htm 
Lober, W. B. and Flowers, J. L. (2011) Consumer Empowerment in Health Care Amid the Internet and Social Media, Seminars in Oncology Nursing, 27 (3), 169-182. doi:10.1016/j.soncn.2011.04.002

Malik, S. H. and Coulson, N. S. (2010) Coping with Infertility Online: an examination of self-help mechanisms in an online infertility support group, Patient Education and Counseling, 81 (2), 315318. doi:10.1016/j.pec.2010.01.007

McMullan, M. (2006) Patients Using the Internet to Obtain Health Information: how this affects the patient-health professional relationship, Patient Education and Counseling, 63 (1-2), 24-28. doi:10.1016/j.pec.2005.10.006

McNair, A. G. K., Brookes, S. T., Kinnersley, P. and Blazeby, J. M. (2013) What Surgeons Should Tell Patients with Oesophago-Gastric Cancer: a cross sectional study of information needs, European Journal of Surgical Oncology (EJSO), 39 (11), 1278-1286. doi:10.1016/j.ejso.2013.08.005

Merolli, M., Gray, K. and Martin-Sanchez, F. (2013) Health Outcomes and Related Effects of Using Social Media in Chronic Disease Management: a literature review and analysis of affordances, Journal of Biomedical Informatics, 46 (6), 957-969. doi:10.1016/j.jbi.2013.04.010

Merolli, M., Gray, K., Martin-Sanchez, F. and Lopez-Campos, G. (2015) Patient-Reported Outcomes and Therapeutic Affordances of Social Media: findings from a global online survey of people with chronic pain, Journal of Medical Internet Research, 17 (1), e20. doi:10.2196/jmir.3915

Moorhead, S. A., Hazlett, D. E., Harrison, L., Carroll, J. K., Irwin, A. and Hoving, C. (2013) A New Dimension of Health Care: systematic review of the uses, benefits, and limitations of social media for health communication, Journal of Medical Internet Research, 15 (4), e85. doi:10.2196/jmir.1933

Mo, P. and Coulson, N. (2010). Empowering processes in online support groups among people living with HIV/AIDS: A comparative analysis of 'lurkers' and 'posters'. Computers in Human Behavior, 26(5), pp.1183-1193.

Nonnecke, B. and Preece, J. (2000) Lurker Demographics: Counting The Silent. ACM CHI 2000 Conference on Human Factors in Computing Systems.

Norman, D. A. (1998) The Invisible Computer, MIT Press.

O'Brien, H. L. and Toms, E. G. (2008) What is User Engagement? A Conceptual Framework for Defining User Engagement with Technology, Journal of the American Society for Information Science and Technology, 59 (6), 938-955. doi:10.1002/asi.20801

O’Reilly, T. and Battelle, J. (2009) Web Squared: Web 2.0: Five Years On. O’Reilly Radar. http://assets.en.oreilly.com/1/event/28/web2009_websquared- whitepaper.pdf.

O’Reilly, T. (2005) Web 2.0: Compact Definition? O’Reilly Radar. http://radar.oreilly.com/2005/10/web20-compact-definition.html

Ormandy, P. (2008) Information Topics Important to Chronic Kidney Disease Patients: a systematic review, Journal of Renal Care, 34 (1), 19-27. doi:10.1111/j.1755-6686.2008.00006.x

Ormandy, P. and Hulme, C. (2013) Measuring Patients' Preferences and Priorities for Information in Chronic Kidney Disease, Information Research, 18 (3).

Petrovčič, A., and Petrič, G. (2014) Differences in Intrapersonal and Interactional Empowerment between Lurkers and Posters in Health-Related Online Support Communities, Computers in Human Behavior, 34, 39-48. doi:10.1016/j.chb.2014.01.008

Preece, J., Nonnecke, B. and Andrews, D. (2004) The Top Five Reasons for Lurking: improving community experiences for everyone, Computers in Human Behavior, 20 (2), 201-223. doi:10.1016/j.chb.2003.10.015 
Putnam, R. D. (2000) Bowling Alone: the collapse and revival of American community, Simon and Schuster.

Rau, P.-L. P., Gao, Q. and Ding, Y. (2008) Relationship Between the Level of Intimacy and Lurking in Online Social Network Services, Computers in Human Behavior, 24 (6), 2757-2770. doi:10.1016/j.chb.2008.04.001

Roblin, D. W. (2011) The Potential of Cellular Technology to Mediate Social Networks for Support of Chronic Disease Self-Management, Journal of Health Communication, 16 (sup1), 59-76. doi:10.1080/10810730.2011.596610

Robson, A. and Robinson, L. (2013) Building on Models of Information Behaviour: linking information seeking and communication, Journal of Documentation, 69 (2), 169-193. doi: $10.1108 / 00220411311300039$

Rozenblum, R. and Bates, D. W. (2013) Patient-Centred Healthcare, Social Media and the Internet: the perfect storm?, BMJ Quality \& Safety, 22 (3), 183-186. doi:10.1136/bmjqs-2012-001744

Rutten, L. J. F., Arora, N. K., Bakos, A. D., Aziz, N. and Rowland, J. (2005) Information Needs and Sources of Information Among Cancer Patients: a systematic review of research (1980-2003), Patient Education and Counseling, 57 (3), 250-261. doi:10.1016/j.pec.2004.06.006

Savolainen, R. (2012) Conceptualizing Information Need in Context, Information Research 17 (4).

Schinkel, S., Schouten, B. C. and van Weert, J. C. M. (2013) Are GP Patients' Needs Being Met? Unfulfilled Information Needs Among Native-Dutch and Turkish-Dutch Patients, Patient Education and Counseling, 90 (2), 261-267. doi:10.1016/j.pec.2012.11.013

Schlosser A. E. (2005) Posting Versus Lurking: Communicating In A Multiple Audience Context. J. Consumer Res. 32 (2):260-265

Schneider, A., von Krogh, G. and Jäger, P. (2013) "What's Coming Next?" Epistemic Curiosity and Lurking Behavior in Online Communities, Computers in Human Behavior, 29 (1), 293-303. doi:10.1016/j.chb.2012.09.008

Siemens, G. (2005). Connectivism: A Learning theory for the digital age. International Journal of Instructional Technology and Distance Learning, 2(1), 3-10. http://202.116.45.236/mediawiki/resources/2/2005_siemens_Connectivism_A_LearningTheoryFor TheDigitalAge.pdf

Shaw, R. J. and Johnson, C. M. (2011) Health Information Seeking and Social Media Use on the Internet Among People with Diabetes, Online Journal of Public Health Informatics, 3 (1), doi:10.5210/ojphi.v3i1.3561

Smith, A. N., Fischer, E. and Yongjian, C. (2012) How Does Brand-Related User-Generated Content Differ Across YouTube, Facebook, and Twitter?, Journal of Interactive Marketing, 26 (2), 102-113. doi:10.1016/j.intmar.2012.01.002

Song, L. and Chang, T.-Y. (2012) Do Resources of Network Members Help in Help Seeking? Social Capital and Health Information Search, Social Networks, 34 (4), 658-669. doi:10.1016/j.socnet.2012.08.002

Szreter, S. and Woolcock, M. (2004) Health by Association? Social Capital, Social Theory, and the Political Economy of Public Health, International Journal of Epidemiology, 33 (4), 650-667. doi:10.1093/ije/dyh013

van Weert, J. C. M., Bolle, S., van Dulmen, S. and Jansen, J. (2013) Older Cancer Patients' Information and Communication Needs: What they want is what they get?, Patient Education and Counseling, 92 (3), 388-397. doi:10.1016/j.pec.2013.03.011 
Vasilica, C. (2015a) Personal communication, from data collected for evaluation of GMKIN, unpublished. University of Salford.

Vasilica, C. (2015b) Impact of Using Social Media to Increase Patient Information Provision, Networking and Communication (PHD thesis). University of Salford.

Vennik, F. D., Adams, S. A., Faber, M. J. and Putters, K. (2014) Expert and Experiential Knowledge in the Same Place: patients' experiences with online communities connecting patients and health professionals, Patient Education and Counseling, 95 (2), 265-270. doi:10.1016/j.pec.2014.02.003

Warner, D. and Procaccino, J. D. (2004) Toward Wellness: women seeking health information, Journal of the American Society for Information Science and Technology, 55 (8), 709-730. doi:10.1002/asi.20016

Welbourne, J., Blanchard, A. and Wadsworth, M. (2013). Motivations in virtual health communities and their relationship to community, connectedness and stress. Computers in Human Behavior, 29 (1), 129-139.

Wenger, E., McDermott, R. and Snyder, W. (2002). Cultivating Communities of Practice. 1st ed. Boston, Mass.: Harvard Business School Press.

Wilson, T. D. (1981) On User Studies and Information Needs, Journal of Documentation, 37 (1), 3-15. doi:10.1108/eb026702

Wilson, T.D. (2004) Information Seeking Behaviour and the Digital Information World" European Science Editing, 30(3)

Wilson, T. D. (1999) Models in Information Behaviour Research, Journal of Documentation, 55 (3), 249 270. doi:10.1108/eum0000000007145

Wilson, T. D. (2007) Evolution in Information Behavior Modeling: Wilson's model. In Fisher, K., Erdelez, S. and McKechnie, L. (eds), Theories of Information Behavior, Information Today (pp. 31-36).

Wilson, T.D. (2006). A Re-examination of Information Seeking Behaviour in the Context of Activity Theory. Information Research, 11 (4) paper 260 http://www.informationr.net/ir/114/paper260.html

Woolcock, M. (2001) The Place of Social Capital in Understanding Social and Economic Outcomes.' Canadian journal of policy research 2 (1), 11-17

Xie, H. (i. (2007) Shifts of Interactive Intentions and Information-Seeking Strategies in Interactive Information Retrieval. Information Research, 12 (4), doi:10.1002/(sici)10974571(2000)51:9<841::aid-asi70>3.0.co;2-0

Zhao, J., Ha, S. and Widdows, R. (2015) The Influence of Social Capital on Knowledge Creation in Online Health Communities. Information Technology and Management. doi:10.1007/s10799-014-0211-3

Zuckerberg, M. (n.d.) Mark Zuckerberg quote, http://www.azquotes.com/quote/685740 [accessed 10 February 2017] 